Article

\title{
Recovery of Gold from Chloride Solution by TEMPO-Oxidized Cellulose Nanofiber Adsorbent
}

\author{
Shila Jafari ${ }^{1, * \mathbb{C}}$, Benjamin P. Wilson ${ }^{2, *}{ }^{\mathbb{D}}$, Minna Hakalahti ${ }^{1}$, Tekla Tammelin ${ }^{1}{ }^{1}$, \\ Eero Kontturi ${ }^{3}$, Mari Lundström ${ }^{2}$ and Mika Sillanpää ${ }^{4}$ \\ 1 VTT Technical Research Centre of Finland, P.O. Box 1000, FI-02044 Espoo, Finland; \\ minna.hakalahti@gmail.com (M.H.); Tekla.tammelin@vtt.fi (T.T.) \\ 2 Laboratory of Hydrometallurgy and Corrosion, Department of Chemical and Metallurgical \\ Engineering (CMET), Aalto University, P.O. Box 16200, FI-00076 Aalto, Finland; mari.lundstrom@aalto.fi \\ 3 Department of Bioproducts and Biosystems (BIO2), Aalto University, P.O. Box 16300, \\ FI-00076 Aalto, Finland; Eero.kontturi@aalto.fi \\ 4 Department of Green Chemistry, Lappeenranta-Lahti University of Technology, FI-50130 Mikkeli, Finland; \\ mika.sillanpaa@lut.fi \\ * Correspondence: shila.sanaz.jafari@gmail.com (S.J.); benjamin.wilson@aalto.fi (B.P.W.)
}

Received: 7 February 2019; Accepted: 4 March 2019; Published: 6 March 2019

check for updates

\begin{abstract}
The goal of this study was to assess the sustainability of a modified cellulose nanofiber material for the recovery of precious gold from chloride solution, with a special focus on gold recovery from acidic solutions generated by cupric and ferric chloride leaching processes. TEMPO-oxidized cellulose nanofiber in hydrogel (TOCN), dry (H-TOCN, F-TOCN) and sheet form (S-TOCN) was examined for gold adsorptivity from chloride solution. Additionally, this work describes the optimum conditions and parameters for gold recovery. The data obtained in this investigation are also modeled using kinetic (pseudo first-order and pseudo second-order), isotherm best fit (Freundlich, Langmuir and Langmuir-Freundlich), and thermodynamic (endothermic process) parameters. Results demonstrate that high levels of gold removal can be achieved with TEMPO-oxidized cellulose nanofibers $(98 \%$ by $\mathrm{H}-\mathrm{TOCNF}$ ) and the interaction characteristics of $\mathrm{H}-\mathrm{TOCN}$ with gold suggests that other precious metals could also be efficiently recovered.
\end{abstract}

Keywords: gold chlorides; TEMPO-oxidized cellulose nanofiber; adsorption; sustainability

\section{Introduction}

At present, the gold content in specific scrap materials like electronic waste can be 10-100 times higher than that available in many naturally-occurring ores [1,2]. In addition to gold, mobile phones, for example, contain ca. 40 other elements [3]. Consequently, the ability to recover gold, along with other rare and valuable metals, in a sustainable manner will play a central role in the development of the metals circular economy.

The dominating state-of-the-art technology for gold containing metal rich waste relies on pyrometallurgical treatment as part of primary copper production or via the secondary raw material smeltery through copper electorefining/electrowinning into a precious metal plant [4]. This process route can recover the main base metals, such as $\mathrm{Cu}$ and $\mathrm{Ni}$, and precious metals, such as $\mathrm{Ag}$, $\mathrm{Au}, \mathrm{Pt}$, and Pd efficiently, however, the loss of several critical and rare earth metals present in the secondary raw materials is evident [2]. By contrast, a hydrometallurgical approach is a promising scalable alternative that can potentially provide the opportunity to recover a wider variety of metals, including gold. In addition, hydrometallurgy offers the possibility for pre-leaching of gold before material is fed into the copper smelter. Hydrometallurgical recovery begins with the transfer of gold into a water 
soluble ionized form in a leaching process, utilising a lixiviant. Cyanide is the lixiviant most applied in gold extraction from ores, but interest has increased towards less toxic, cyanide-free processes like the ones utilising concentrated sodium or calcium chloride media with cupric or ferric ions as oxidant $[5,6]$. Several precious metal plants are known to operate in hydrochloric acid media at very high acidity [7] and, furthermore, gold chloride is purported to undergo faster dissolution during leaching than the corresponding cyanide salt [4].

The main challenge after leaching is to recover the ionized gold, which can be performed by, e.g., solvent extraction, ion exchange, reduction, or adsorption. Of these, adsorption offers a method that is low cost, scalable, robust, efficient, and environmentally friendly. Generally, the low concentration of gold (1-100 mg/L) in the lixiviant means that an adsorbent, particularly nanomaterials at the atomic level with higher surface area, need to be further developed in order to enhance the recovery of chemicals or contaminants in aqueous phases by adsorption processes [8,9]. Moreover, the utilization of sustainable/biodegradable substances derived from nature have emerged as novel materials for the adsorption and concentration of metallic ions from aqueous solution [10-23]. In this paper, we introduce a highly-charged nanocellulose [15] template as an outstanding, biologically-derived adsorbent for gold recovery from aqueous solutions. Particularly suitable for this purpose are cellulose nanofibers extracted with oxidation catalysed by the 2,2,6,6-tetramethylpiperidinyl-1-oxyl radical (TEMPO) [16,17]. This oxidation process is performed in aqueous solution at room temperature and the resulting TEMPO-oxidized cellulose nanofibers (TOCNs) are slender threads of high aspect ratio (nm scale width, $\mu \mathrm{m}$ scale length) and exceptionally high mechanical properties [14,24]. Due to TEMPO-oxidation in their isolation process, the nanofibers are highly charged and their recovery from aqueous environment can be difficult because of their small size and intrinsic gelling properties. To incorporate TOCNs in a macroscopic matrix, we have utilized a simple procedure: The initial oxidation was left incomplete, leaving aldehyde moieties in addition to carboxylates on the TOCN surface. Here, a new concept of utilizing entirely bio-based, cross-linked TEMPO-oxidized cellulose nanofibers (TOCNs) for selective gold recovery is presented. Specifically, we demonstrate how the selective recovery occurs in dilute, mildly acidic solutions also containing copper ions, thereby reflecting conditions in a genuine environment typical for a development-stage cyanide-free process, namely cupric chloride leaching of gold [25]. The fundamental effect of time and temperature were investigated to optimize the conditions and parameters for gold recovery in this system. The technique with TOCNs combines two important aspects of green and sustainable engineering: (i) supporting the development of a new cyanide-free alternative for water-based, hydrometallurgical gold processing from, e.g., electronic waste and (ii) utilisation of widely available, renewable TOCNs to realise that alternative.

The aim of the present work is to investigate the ability of bio-based material adsorbent, TOCNs, with a special focus on gold recovery in acidic solutions-as is usual in the case of cupric and ferric chloride leaching processes.

\section{Materials and Methods}

\subsection{Materials}

All chemicals, purchased from Sigma-Aldrich (Espoo, Uusimaa, Finland), were of analytical grade and used without the need for any further purification. Gold stock solution (1000 mg/L in 5\% $\mathrm{HCl} w / w \%$ ), copper (II) chloride dehydrate and sodium chloride were used for the measurement solutions. Never dried bleached softwood pulp sourced from a Finnish pulp mill and used in the preparation of the nanocellulosic materials. TEMPO (2,2,6,6-tetramethylpipedine-1-oxyl radical), sodium bromide, sodium hypochlorite solution (10\% $w / v$, poly vinyl alcohol (PVA) (Mowiol 56-98, $\mathrm{M}_{\mathrm{W}} 195,000 \mathrm{~g} / \mathrm{mol}$, DP 4300) were used to prepare adsorbents. Solution $\mathrm{pH}$ was adjusted by the addition $3 \mathrm{M} \mathrm{NaOH}$ solution with stirring and samples were centrifuged in order to separate the suspension from aqueous solution. Finally, the concentration of metals in the solutions were 
determined using inductively-coupled plasma optical atomic emission spectrometry, ICP-OES (model 7100DV, Perkin Elmer).

\subsection{Adsorbent Preparation}

TEMPO-oxidized cellulose nanofiber (TOCN) in hydrogel and film form were used. For preparation of the TEMPO-oxidized cellulose nanofiber (TOCN), the first step was to synthesize cellulose nanofiber (CNF). Afterward the CNF was converted to TOCN hydrogel before being modified to the different forms of dry and sheet film.

\subsubsection{TEMPO-Oxidized Cellulose Nanofibers (TOCN)}

A birch wood pulp obtained from a Finnish pulp mill was subjected to oxidation with 2,2,6,6tetramethylpiperidine-1-oxyl (TEMPO) and sodium hypochlorite in order to produce TOCN following the procedure described by Saito et al. [22]. In brief, a high-pressure fluidizer (Microfluidics M110Y Microfluidics Corporation, MA, USA) that featured two Z-type chambers $(400 \times 100 \mu \mathrm{m}$ diameter $)$ was applied to fibrillate TEMPO-oxidized pulp. The pulp was passed through the fluidizer twice at $1800 \mathrm{bar}$ operating pressure. Charge of the oxidized pulp was determined using a standard conductometric titration method (SCAN-CM 65:02, 2002) and was determined to be ca. $1.39 \mathrm{mmol} \mathrm{g}^{-1}$. The aldehyde groups formed during the TEMPO oxidation were oxidized further into carboxylic groups in order to produce a viscous and transparent gel that had a dry matter content of $1.1 \mathrm{wt} \%$, (Figure 1a). TOCN hydrogels (soggy adsorbent, as it was gained from preparation) were stored at $+4-5{ }^{\circ} \mathrm{C}$ until further use.

a)
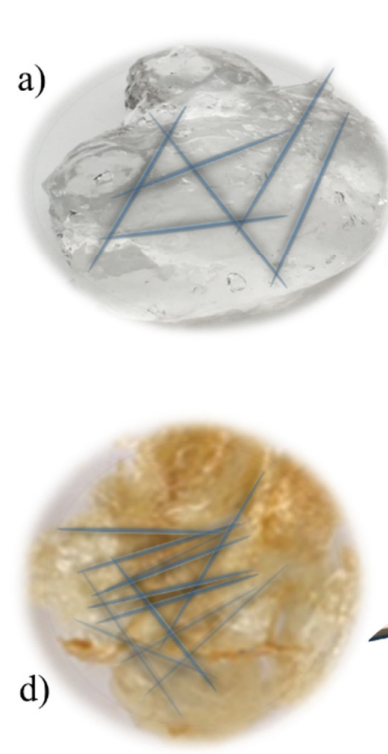

b)
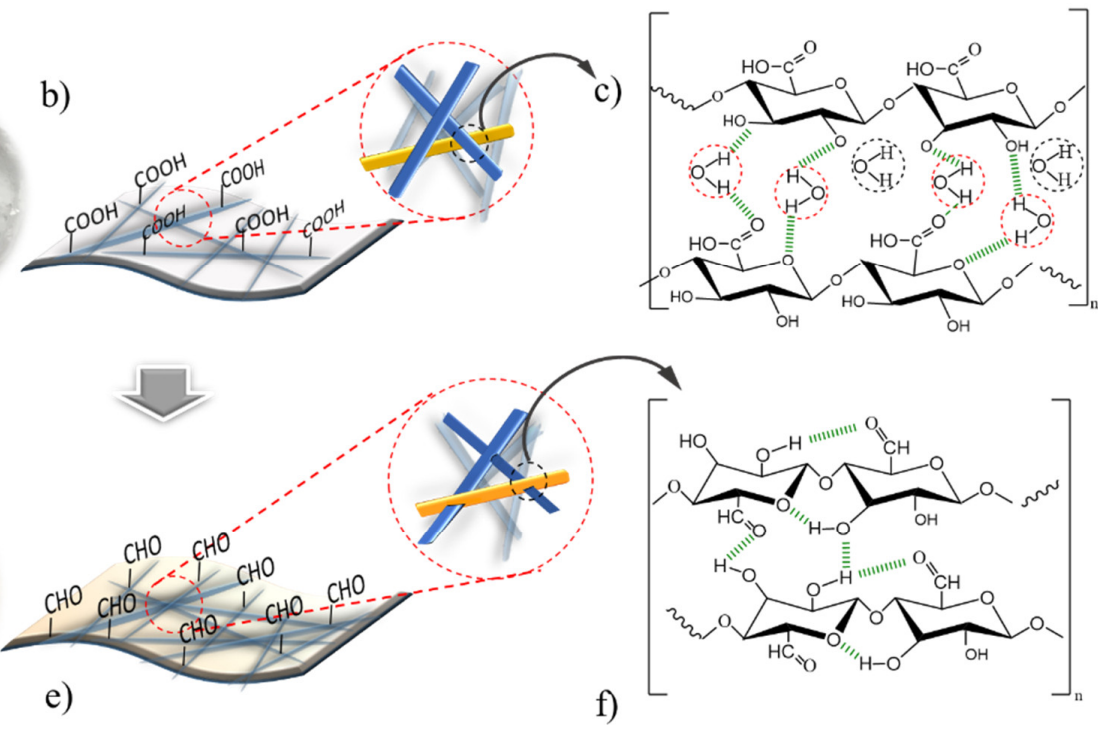

Figure 1. Schematic of TOCNC (a-c) hydrogel form of TEMPO-oxidized CNF (d-f) film form of TEMPO-oxidized CNF.

\subsubsection{Oven Dried TEMPO-Oxidized Cellulose Nanofibers (H-TOCN)}

The resulting TOCN gel was subsequently cured at $90^{\circ} \mathrm{C}$ for $12 \mathrm{~h}$ and then allowed to slowly cool, leading to cross linking of the TOCNs due to the reactivity of the aldehydes (Figure 1a-c). The resulting material was film-like (Figure 1d-f) and easy to dip into a solution. 


\subsection{Batch Adsorption Study}

The solution simulates a gold chloride leaching solution with both gold (the valuable metal) and copper (as a typical impurity) present in the solution. The adsorption of gold in cupric chloride solution on the TOCN material was studied in batch mode and the effect of different parameters, including adsorbent dose (25-250 mg/10 mL), initial Au concentration (10-100 mg/L), temperature $\left(25-90{ }^{\circ} \mathrm{C}\right)$, and contact time were assessed. In addition, the $\mathrm{pH}$ and ionic strength of the solution were adjusted by $\mathrm{NaOH}$ and $\mathrm{NaCl}$ additions. It should be noted that all the adsorption experiments were conducted out at $\mathrm{pH}=2$.

In the work outlined here, the simulated gold mining solution was varied between $10-100 \mathrm{mg} / \mathrm{L}$ in a $0.02 \mathrm{M}$ copper chloride solution, $\mathrm{pH}=2$ and with the optimized quantity of adsorbents $(500 \mathrm{mg}$, $150 \mathrm{mg}$ for TOCN and H-TOCN, respectively) in order to investigate recovery of the gold in binary solution. Equilibrium adsorption experiments were carried out to gauge the efficiency of TOCN in removing gold from chloride solution. The solution was then agitated in a bath shaker (Stuart SBS40) at $130 \mathrm{rpm}$ for $48 \mathrm{~h}$ to ensure that adsorption process reached equilibrium. The subsequent removal of the adsorbent TOCN film, i.e., solid/liquid separation of the adsorbent was straightforward.

In order to investigate the adsorption, isotherms experiments were performed at varying solution temperatures with an initial gold concentration $(100 \mathrm{mg} / \mathrm{L})$ in chloride solution $(0.02 \mathrm{M})$. In contrast, the kinetic experiments were conducted with optimized adsorbents quantities: 10.0 g gel form (TOCN), $0.5 \mathrm{~g}$ and dry form (H-TOCN). The initial concentration of the solution was $0.2 \mathrm{~L}$ of $100 \mathrm{mg} / \mathrm{L} \mathrm{Au}$ and $0.02-1 \mathrm{M} \mathrm{CuCl}_{2}$ at a $\mathrm{pH}=2$ and a temperature of $25^{\circ} \mathrm{C}$. The adsorption percentage $(R \%)$ and adsorption capacity values at equilibrium $\left(q_{e}\right)$ and time $t\left(q_{t}\right)$ were calculated using the following equations:

$$
\begin{gathered}
R \%=\frac{\left(C_{0}-C_{e}\right)}{C_{0}} \times 100 \\
q_{e}=\frac{\left(C_{0}-C_{e}\right) V}{W}, q_{t}=\frac{\left(C_{0}-C_{t}\right) V}{W}
\end{gathered}
$$

where $C_{0}$ (initial), $C_{e}$ (equilibrium) and $C_{t}$ (time) are the $\mathrm{Au}$ (III) concentration (mg/L) in solution, respectively, $V$ is the aqueous solution volume $(\mathrm{L})$ and $W$ represents the adsorbent sample weight added to solution $(\mathrm{g})$.

\subsection{Effect of Ionic Strength}

As the primary aim of this work was the recovery of gold from chloride solutions, the influence of ionic strength (IS) was also investigated by the adjustment of the concentration of $\mathrm{Cl}^{-}$ions in the solution. This was achieved using $\mathrm{NaCl}$ additions to produce solutions with $\left[\mathrm{Cl}^{-}\right]$of $0.02,0.1,0.5$, and $1 \mathrm{M}$, taking into account the amount of $\mathrm{Cl}^{-}$already present due to $\mathrm{CuCl}_{2}$ [26].

\subsection{Characterization of Materials}

TOCN samples were characterized by a zetasizer (Nano-ZS90, Malvern, UK). $\mathrm{N}_{2}$ adsorptiondesorption isotherms and pore size of both the H-TOCN and F-TOCN samples was measured at 77.35K using a BELsorp-mini II instrument (BEL, Japan). All samples were outgassed at a temperature of $70{ }^{\circ} \mathrm{C}$ for 20 hours prior to the adsorption-desorption experiments. For all measurements, accuracy at each pressure step was improved by the use of a dead volume reference cell. The Brunauer, Emmett, and Teller (BET) method was used to calculate the sample surface area over a relative pressure range of 0.05 to 0.45 on the adsorption isotherm [27] In contrast, pore size distribution was determined using the Barret-Joyner-Halenda (BJH) method based on the isotherm desorption branch [28]. All calculations were performed using the proprietary BELMaster (BEL, Japan) analysis software (Version 6.4.1.0).

Characterization of the TOCN and S-TOCNF was also carried out using atomic force microscopy (AFM) from Anasys Instruments Inc. (Santa Barbara, CA, USA) in tapping mode with MicroMasch HQ: NSC15/Al BS probes. Typical cantilever resonance frequency was $325 \mathrm{kHz}$ and radius of the curvature 
of the cantilever $8 \mathrm{~nm}$ according to the manufacturer. No other image processing was performed except flattening and at least three images per sample were taken. AFM images were analysed using the Analysis Studio software (version 3.11). The self-standing TEMPO CNF-PVA film was imaged as such in dry state. Samples from the TEMPO CNF fibrils were prepared on Au surfaces by spincoating as described by Ahola et al. [29] Root mean square roughness values $(R q)$ for the TEMPO CNF-PVA film in dry state were extracted from three topographic $3 \mu \mathrm{m} \times 3 \mu \mathrm{m}$ AFM images and the average roughness value are reported.

\section{Results and Discussion}

\subsection{Adsorbent Characterization}

Nanoscale surface topography of the adsorbent was investigated by AFM. This technique provides three-dimensional images that allows spatial information related to changes in adsorbent surface roughness to be determined. Figure 2 shows the AFM images for both the TOCN and film form of the TOCN. In Figure 2a, the topographic profiles of height images emphasized with white line.
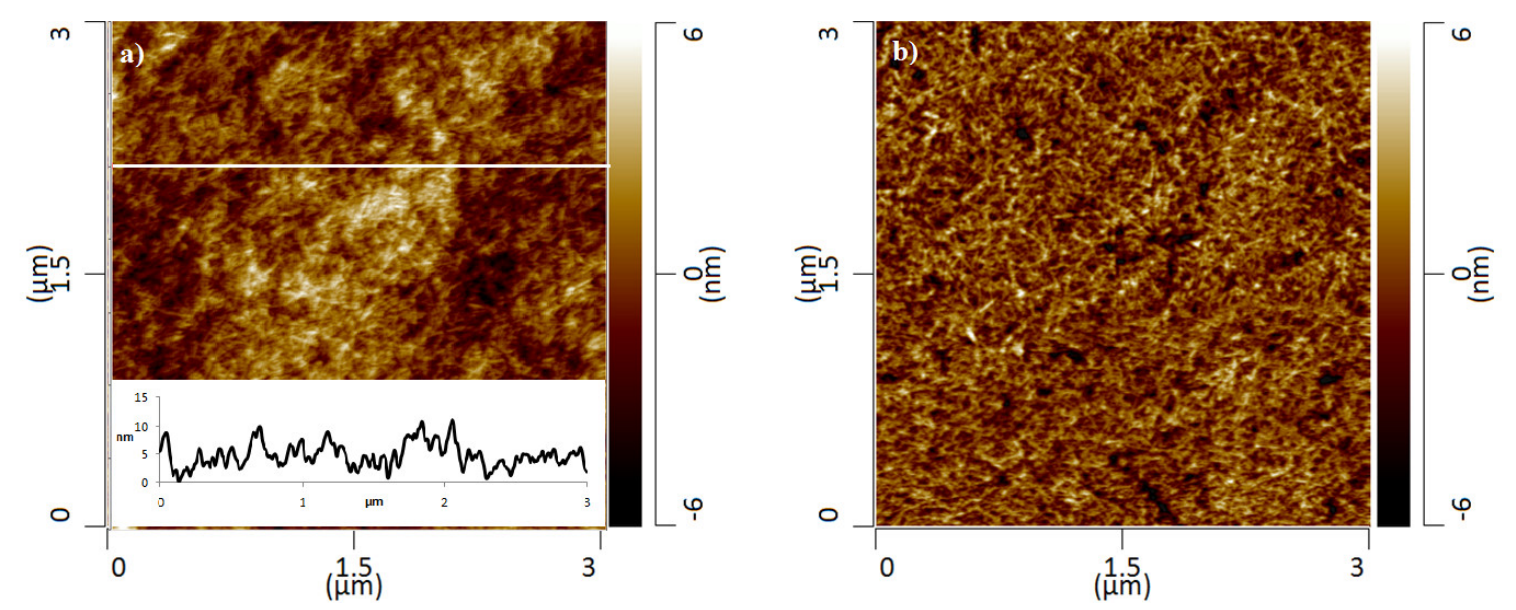

Figure 2. (a) AFM height image $(3 \mu \mathrm{m} \times 3 \mu \mathrm{m})$ of a H-TOCN with topographic profile and (b) TOCN $(3 \mu \mathrm{m} \times 3 \mu \mathrm{m})$ spincoated on an Au surface.

Nitrogen adsorption-desorption isotherms at 77.35K of the investigated dried TOCNs (H-TOCN and F-TOCN) are presented in Figure 3., The shape of the isotherm displays an intermediate between types II and IV based on the IUPAC classification [30] which is indicative of an initial monomolecular adsorbate layer (i.e., type II assumption) followed by multi-layer adsorption. Moreover, as the isotherm features a slight hysteresis loop, usually generated by the capillary condensation of the adsorbate in the mesoporous structure, type IV behavior is also observed. Furthermore, BET analysis results also allow the total surface area $\left(\mathrm{S}_{\mathrm{BET}}\left(\mathrm{m}^{2} / \mathrm{g}\right)\right)$ and pore radius of the samples to be determined. The $\mathrm{S}_{\mathrm{BET}}$ of the H-TOCN and F-TOCN samples are approximately 0.5 and $6.3 \mathrm{~m}^{2} / \mathrm{g}$, whereas the average pore radius are of 1.21 and $1.85 \mathrm{~nm}$, respectively.

In addition, the surface charge of the TOCN hydrogel was also measured by zetasizer (Malvern Zetasizer Nano-ZS90) and the results show that the average $\zeta$ potential of the solution is $>65 \mathrm{mV}$. This result indicates that solutions of TOCN are highly charged and should have excellent colloidal stability. 


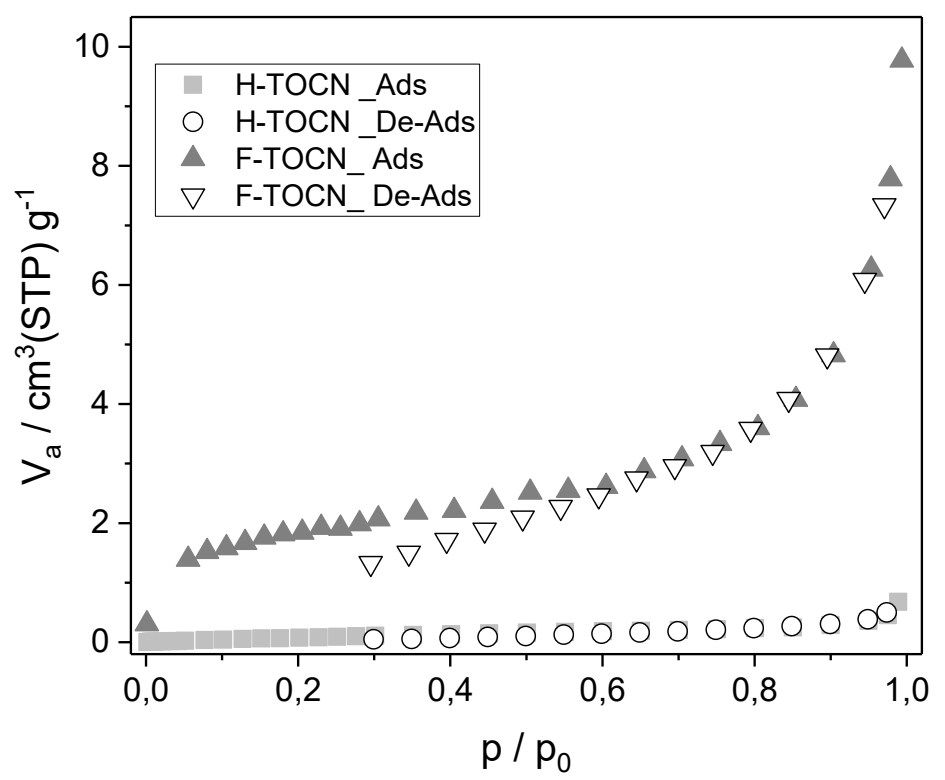

Figure 3. Nitrogen adsorption/desorption isotherms of H-TOCN and F-TOCN.

\subsection{Recovery of Gold via the Adsorption Process}

\subsubsection{Effect of Adsorbent Dose}

At first, the amount of adsorbent was optimized through various doses of the adsorbent; 25,50, $75,100,150,200$, and $250 \mathrm{mg}$ were added into $10 \mathrm{~mL}$ of gold (C0 = $100 \mathrm{mg} / \mathrm{L})$ containing $0.02 \mathrm{M}$ $\mathrm{CuCl}_{2}$ solution for either 24 or $48 \mathrm{~h}$. The solution simulates a gold chloride leaching solution with both gold (the valuable metal) and copper (as typical impurity) present in the solution. Figure 4 shows that the recovery of $\mathrm{Au}$ increases with increasing adsorbent concentration exposed into the solution. Furthermore, an increase in dosage up to $250 \mathrm{mg}$ (dry weight of TOCN) was also shown to increase Au recovery, probably as a result of increased adsorbent active site accessibility with increased adsorbent concentration. Nevertheless, it was also observed that the enhancement of gold recovery at the highest adsorbent dose $(250 \mathrm{mg})$ is negligible compared to $200 \mathrm{mg}$ dose; hence, the optimum removal of gold ( $\sim 98.0 \%$ ) can be obtained by using $150 \mathrm{mg} / 10 \mathrm{~mL}$ of the TOCNs at equilibrium after $48 \mathrm{~h}$.

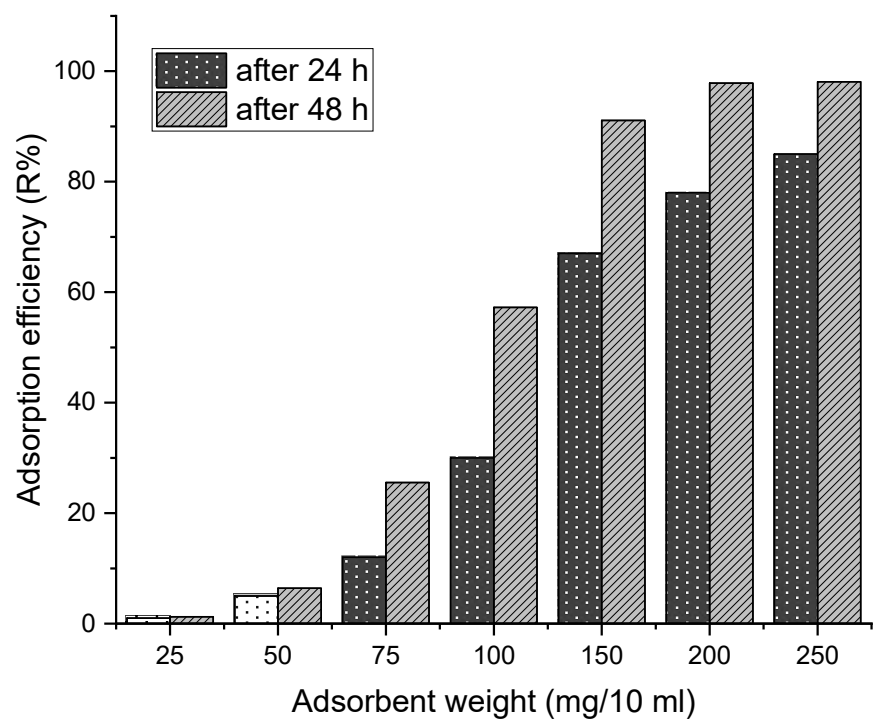

Figure 4. Adsorption efficiency of $\mathrm{H}-\mathrm{TOCN}$ for recovery of gold at different dose: doses $=25-250 \mathrm{mg} /$ $10 \mathrm{~mL}\left(\mathrm{C}_{0}[\mathrm{Au}]=100 \mathrm{mg} / \mathrm{L}, \mathrm{C}_{0}\left[\mathrm{Cl}^{-}\right]=0.02 \mathrm{M}, \mathrm{C}_{0}\left[\mathrm{Cu}^{+2}\right]=0.02 \mathrm{M}\right.$ after $24 \mathrm{~h}$ and $48 \mathrm{~h}, 130 \mathrm{rpm}, \mathrm{pH}=2$, $10 \mathrm{~mL}$ sol.). 
In addition, the results in Figure 4 illustrate that high gold recoveries of $>95 \%$ can be readily achieved by H-TOCNs under ambient conditions after $48 \mathrm{~h}$ and mild agitation (130 pm).

Adsorption of gold in chloride solution by H-TOCN was performed at other low rotation speeds, (data not presented here) though the results show the best gold recovery efficiencies were obtained with an agitation of $130 \mathrm{rpm}$. Moreover, an increase in the level of agitation results in an increase in the gold recovery efficiency for all adsorbent weights used and this is in line with previous observations for other modified cellulose adsorbents for $\mathrm{Au}(\mathrm{III})$ adsorption available in the literature [10].

\subsubsection{Effect of Temperature}

In the work outlined here, the simulated gold mining solution was varied between $10-100 \mathrm{mg} / \mathrm{L}$ at $0.02 \mathrm{M}$ copper chloride solution and $\mathrm{pH}=2$ in order to investigate recovery of gold from a binary solution. In addition, the effect of temperature on gold recovery was studied over a temperature range between $25-90{ }^{\circ} \mathrm{C}$ at the same initial $\mathrm{pH}(2.0)$ and cupric chloride concentration (0.02 M) (Figure 5a). As can be observed from Figure 5a, the recovery of gold was enhanced up to $99 \%$ with increasing temperature. Most likely, the enhancement of gold recovery at higher temperature may be accounted for by the change in chemical morphology of the chloro-gold complexes with temperature [31].

(a)

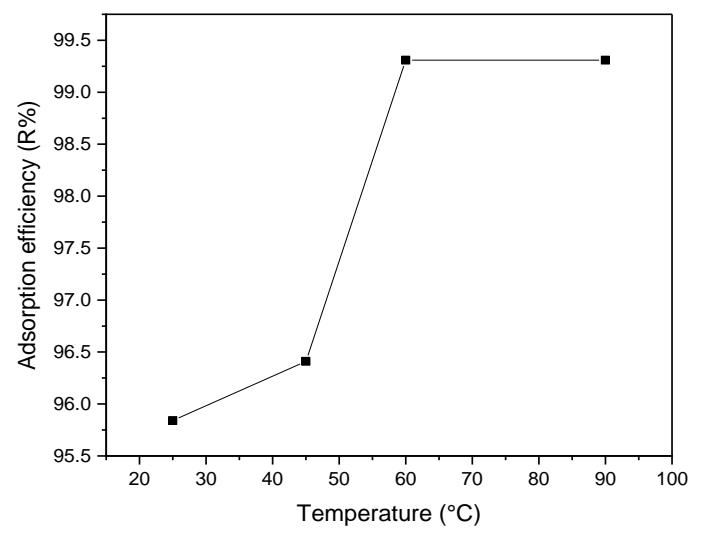

(b)

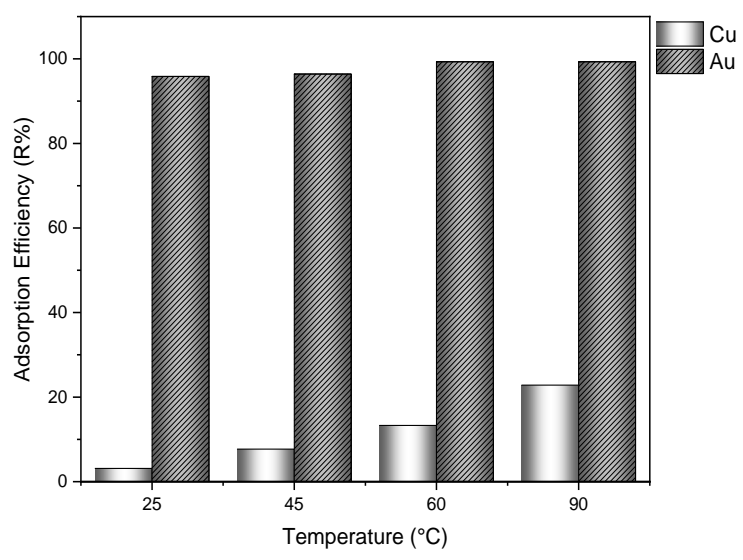

Figure 5. (a) Gold adsorption efficiency onto the TOCNs at the temperature range between $25-90{ }^{\circ} \mathrm{C}$. (b) A comparison of $\mathrm{Au}$ and $\mathrm{Cu}$ recovery at the simulated gold mining solution at the temperature range between $25-90{ }^{\circ} \mathrm{C}(\mathrm{C} 0[\mathrm{Au}]=100 \mathrm{mg} / \mathrm{L}, \mathrm{C} 0[\mathrm{Cl}-]=0.02 \mathrm{M}, \mathrm{C} 0[\mathrm{Cl}-]=0.02 \mathrm{M}, 48 \mathrm{~h}, 130 \mathrm{rpm}$, $\mathrm{pH}=2,10 \mathrm{~mL}$ sol.).

As previously outlined, all experiments were performed at $\mathrm{pH}=2$. In this regard, it is worth to take into account calculation of Pourbaix Diagram to estimate Au-species at $\mathrm{pH}=2$. As can be seen from the calculation at $\mathrm{pH} 2$ the main components in the Pourbaix diagram comprise of $\mathrm{Au}(\mathrm{s})$, $\mathrm{AuCu}(\mathrm{s})$, and $\mathrm{Au}(\mathrm{s})$ associated with $\mathrm{Cu}^{2+}$ in solution (See supplementary Figure S1). Accordingly, 
it can derive that $\mathrm{Cu}$ ions are in competition with $\mathrm{Au}$ - species in the solution and selectivity toward gold ions is main concern in the copper (II) chloride solution. Figure $5 \mathrm{~b}$ reveals that TOCN has good ability to adsorb $\mathrm{Au}$ in the binary solution in contact with $\mathrm{Cu}$. In other words, TOCNs can selectively adsorb gold ions from the copper (II) chloride solution. Indeed, the sustainable material TOCN, is a promising alternative to use in industrial applications to overcome the limitations in gold recovery from chloride solutions when in competition with $\mathrm{Cu}^{2+}$ from the oxidant in cyanide-free leaching processes. Nevertheless, the transformation from the laboratory scale to industrial application still needs to be studied in more detail.

The results in Figure 5a were further analyzed to determine the total energy changes occurring during adsorption, in order to ascertain the gold recovery mechanism. As the total adsorption efficiency of gold is large at high temperature, these results were used to establish gold adsorption efficiency onto TOCN as a function of temperature versus time (See supplementary Table S1 and Figure S2).

\subsubsection{Effect of Ionic Strength}

Another important factor that affects the adsorption behavior of gold is the chemical morphology of chloro-gold complexes. The ratio of each chloro-gold complex concentration relates to both chloride and hydrogen ion concentration, as well as temperature, as they can exist as different species depending on $\mathrm{pH}$ (Figure 6) [11].

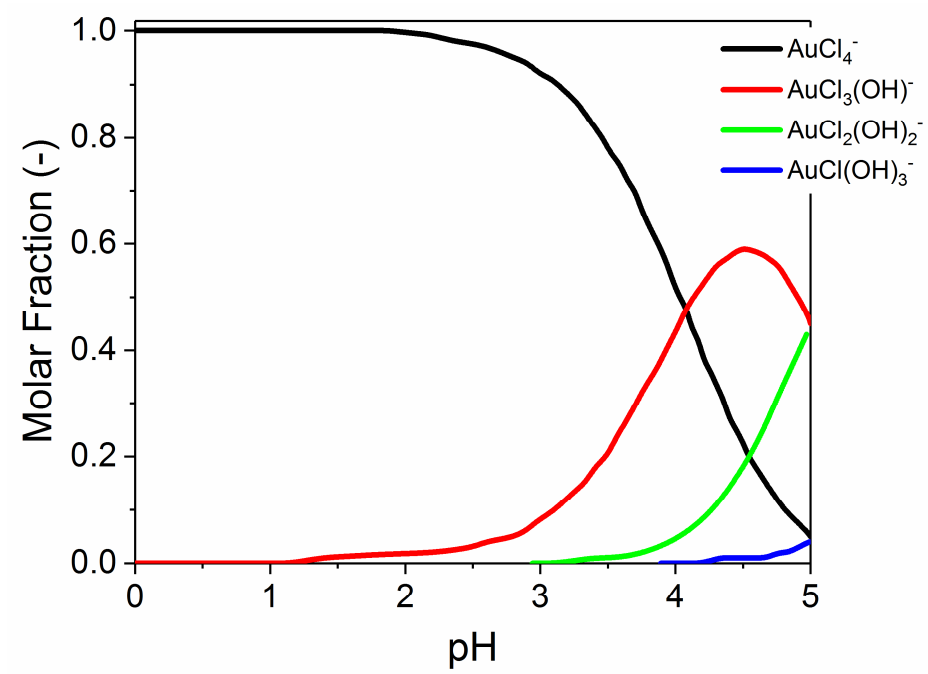

Figure 6. Fraction diagrams of chloro-gold complexes calculated with equilibrium constants at $\mathrm{pCl} 2.0$ and $293 \mathrm{~K}\left[\right.$ After $\left.^{12}\right]$.

The equilibrium constants of gold-chloro complexes are as follows (35):

$$
\begin{gathered}
\mathrm{Au}(\mathrm{OH})_{4}{ }^{-}+\mathrm{H}^{+}+\mathrm{Cl} \rightleftharpoons{ }^{-} \mathrm{AuCl}(\mathrm{OH})_{3}{ }^{-}+\mathrm{H}_{2} \mathrm{O}, \mathrm{K}_{1}=10^{8.51} \\
\mathrm{AuCl}(\mathrm{OH})_{3}{ }^{-}+\mathrm{H}^{+}+\mathrm{Cl}^{-} \rightleftharpoons \mathrm{AuCl}_{2}(\mathrm{OH})_{2}{ }^{-}+\mathrm{H}_{2} \mathrm{O}, \mathrm{K}_{2}=10^{8.06} \\
\mathrm{AuCl}_{2}(\mathrm{OH})_{2}{ }^{-}+\mathrm{H}^{+}+\mathrm{Cl}^{-} \rightleftharpoons \mathrm{AuCl}_{3}(\mathrm{OH})^{-}+\mathrm{H}_{2} \mathrm{O}, \mathrm{K}_{3}=10^{7.00} \\
\mathrm{AuCl}_{3}(\mathrm{OH})^{-}+\mathrm{H}^{+}+\mathrm{Cl}^{-} \rightleftharpoons \mathrm{AuCl}_{4}{ }^{-}+\mathrm{H}_{2} \mathrm{O}, \mathrm{K}_{4}=10^{6.07}
\end{gathered}
$$


As can be seen from the above equations and Figure 6, the predominant complex of gold at $\mathrm{pH}<3$ is mainly $\mathrm{AuCl}_{4}^{-}$. Indeed, at $\mathrm{pH}$ higher than $3, \mathrm{AuCl}_{4}{ }^{-}$is likely to undergo hydrolysis, which causes the complex to change to $\mathrm{AuCl}_{3}(\mathrm{OH})^{-}$in the aqueous chloride solution. Moreover, Ogata et al. [11] reported that the gold recovery from the aqueous chloride solution by tannin gel particles was almost independent of the initial $\mathrm{pH}$ in the range between 2.0-3.8. In this regard, all the experiments were conducted at same initial $\mathrm{pH} 2$ and stable temperature $\left(25^{\circ} \mathrm{C}\right)$ in order to investigate the effect of chloride ions concentration, in the range of $0.02-1 \mathrm{M}$, on the gold adsorption behavior. The results obtained from these experiments are shown in Figure 7 and it can be seen that the recovery of gold decreases with higher ionic strength values.

It is reported that increasing inter-fibrillar electrostatic repulsion and reduction of the adhesion between the fibrils leads to the nanofibrillation of cellulose [22]. Therefore, the background electrolyte concentration reduces the electrostatic repulsion between the fibers and in doing so, the specific surface area $[32,33]$. This is observed in Figure 7 as an increase in the background electrolyte concentration (higher IS values) leads to a drop in the gold recovery due to a decrease in nanofibrillation tendency. It is also possible that low IS values may enhance electrostatic repulsion and consequently cause the TEMPO cellulose nanofibers to adopt a more open configuration that produces more access to the adsorbent pores for gold removal from the solution.

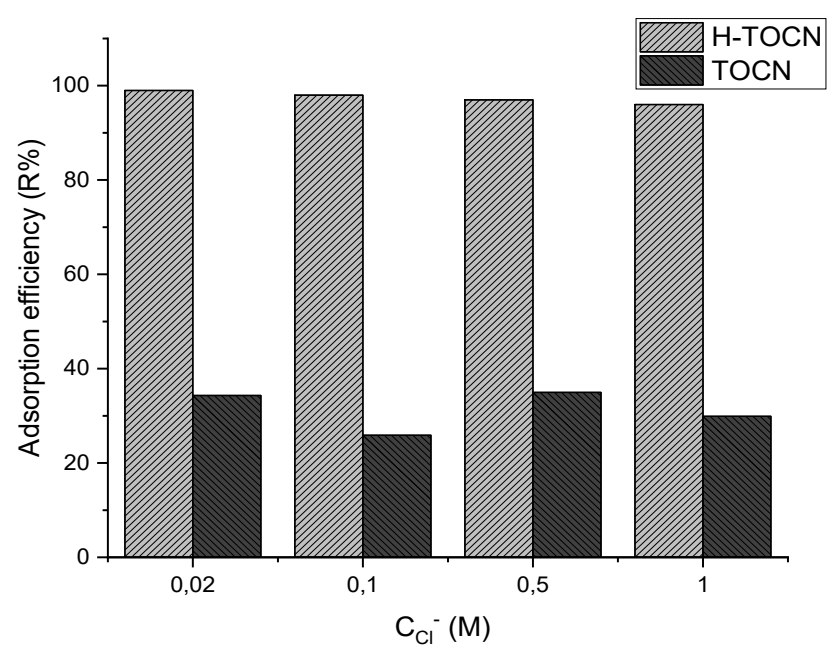

Figure 7. Effect of ionic strength on gold recovery at high concentration of gold $\left(\mathrm{C}_{0}[\mathrm{Au}]=100 \mathrm{mg} / \mathrm{L}\right.$, $\mathrm{C}_{0}\left[\mathrm{Cl}^{-}\right]=0.02-1 \mathrm{M}, 48 \mathrm{~h}, 130 \mathrm{rpm}, \mathrm{pH}=2,10 \mathrm{~mL}$ sol.).

The influence of the presence of chloride ions in the aqueous solution was also studied at lower concentrations of gold $(10 \mathrm{mg} / \mathrm{L})$ under identical conditions. The increase of IS in the aqueous phase increases the adsorption efficiency, which can be attributed to higher ionic concentration. In addition, as can be seen from Equation (7), a shift to left side-which occurs when gold is present in the aqueous phase-results in a non-adsorbable $\mathrm{HAuCl}_{4}$ species (Figure 8).

$$
\mathrm{HAuCl}_{4}=\mathrm{AuCl}_{4}^{-}+\mathrm{H}^{+}
$$

Consequently, by increasing the IS from 0.02 to $1 \mathrm{M}$, the gold adsorption efficiency increased, a finding that correlates with the previous observations of Alguacil et al. who studied gold (III) adsorption using $\mathrm{HCl}$ concentrations ranging between 0.03 to $0.5 \mathrm{M}$ [34]. 


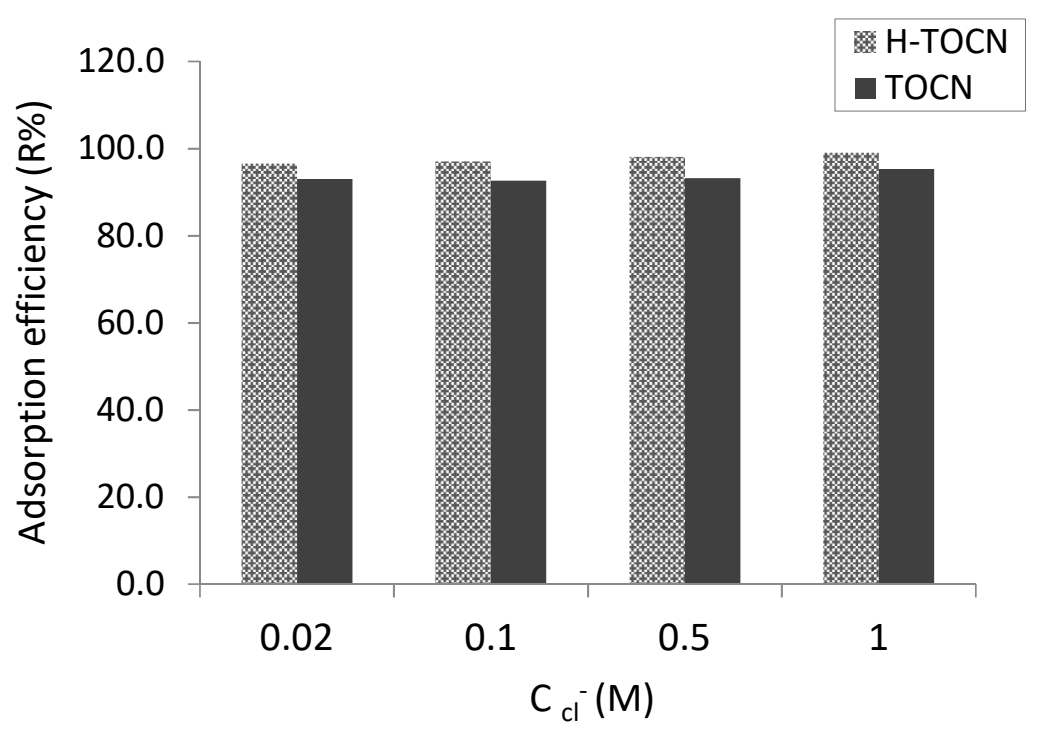

Figure 8. Effect of ionic strength on gold recovery at low concentration of gold $\left(\mathrm{C}_{0}[\mathrm{Au}]=10 \mathrm{mg} / \mathrm{L}, \mathrm{C}_{0}\right.$ $\left[\mathrm{Cl}^{-}\right]=0.02-1 \mathrm{M}, 48 \mathrm{~h}, 130 \mathrm{rpm}, \mathrm{pH}=2,10 \mathrm{~mL}$ sol.).

\subsubsection{Kinetic Study}

In order to both investigate the mechanism of adsorption and control adsorption rate, it is important to also study the kinetics of gold adsorption onto the adsorbents. Plot of changes in adsorption capacity $\left(q_{t}\right)$ vs. time $(t)$ are shown in Figure 9, at initial concentration of $100 \mathrm{mg} / \mathrm{L}$ gold in $0.02 \mathrm{M}$ chloride solution and the kinetic models were examined over a $48 \mathrm{~h}$ period.

The adsorption kinetic data, the application of two of the most widely utilized kinetic modelspseudo-first order and pseudo-second order were investigated [35]. The linear forms of these models are:

$$
\begin{gathered}
\ln \left(\frac{\left(q_{e}-q_{t}\right)}{q_{e}}\right)=-k_{1} t \\
\frac{t}{q_{t}}=\frac{1}{k_{2} q_{e}^{2}}+\frac{t}{q_{e}}
\end{gathered}
$$

where $q_{e}$ is the equilibrium value of $q_{t}, k_{1}$ and $k_{2}$ are the rate coefficient for the pseudo first-order (PFO) and pseudo second-order (PSO) models, respectively.
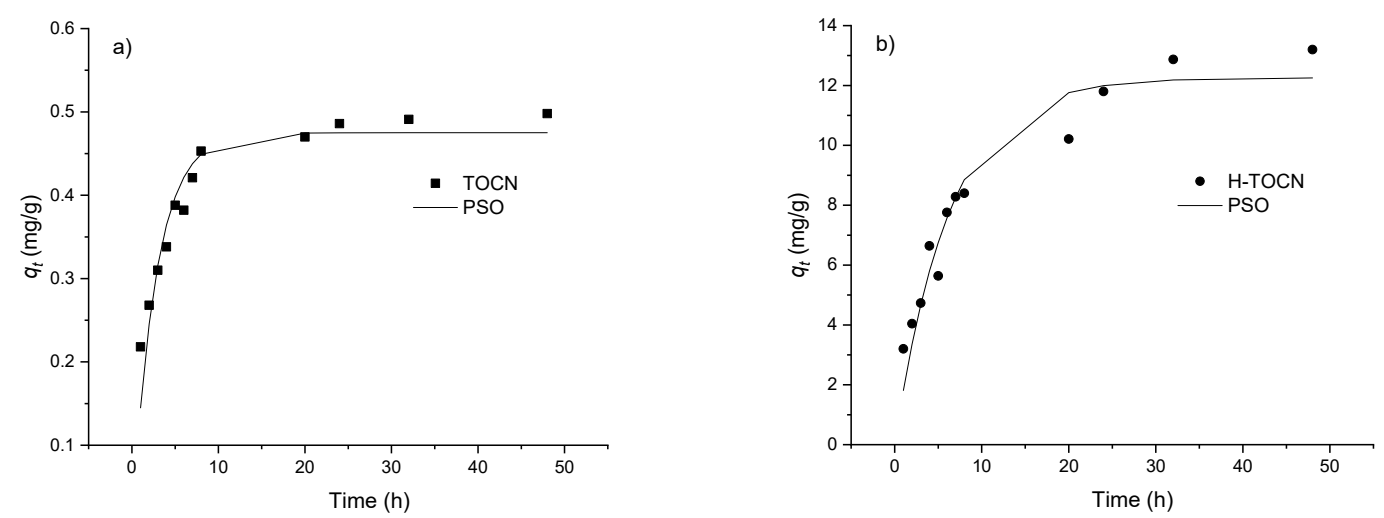

Figure 9. Adsorption kinetic data of gold onto the mentioned adsorbents (a) TOCN and (b) H-TOCN, experimental data are shown by symbols and the solid line the values predicted by the PSO model. (C0 $[\mathrm{Au}]=100 \mathrm{mg} / \mathrm{L}, \mathrm{C} 0[\mathrm{Cl}-]=0.02 \mathrm{M}, 48 \mathrm{~h}, 130 \mathrm{rpm}, \mathrm{pH}=2,200 \mathrm{~mL}$ sol. $)$.

In this case, the adsorption rate is relative to the process driving force or kinetics, which is related here to the gold solution concentration (pseudo first-order). In addition, adsorption capacity 
can also be related to the number of adsorbent active sites occupied and aqueous solution solute concentration (pseudo second order kinetics) [35]. The comparison of fitting results produced by Equations (8) and (9) showed that the kinetic data has a higher correlation with the pseudo second order model cf. pseudo first-order model (Table 1). In addition, another factor $(\beta \theta)$ in relation to initial the concentration $\left(C_{0}\right)$ and concentration at any time $\left(C_{t}\right)$ [36], allows a comparison between $C 0$ and $\beta \theta$ to be determined at the initial gold concentration of $100 \mathrm{mg} / \mathrm{L}$ at any time (Table 2). It was found that the $\beta \theta$ values were inconsequential when compared with the initial concentration of gold used, hence, it was determined that the pseudo second-order model best describes the adsorption kinetics of gold onto TEMPO-oxidized nanofiber cellulose. Indeed, the rate-limiting step may be related to either chemisorption or chemical adsorption between the adsorbate and adsorbent.

Table 1. Constants obtained from PFO and the models for gold adsorption onto different types of TOCN adsorbents (TOCN, H-TOCN, F-CNF, and S-TOCN).

\begin{tabular}{ccccccc}
\hline \multicolumn{3}{c}{ Pseudo First-Order } & \multicolumn{5}{c}{ Pseudo Second-Order } \\
\hline $\boldsymbol{r}^{\mathbf{2}}$ & $\boldsymbol{k}_{\mathbf{1}} \mathbf{( 1 / \mathbf { h } )}$ & $\boldsymbol{q}_{\boldsymbol{e}}\left(\mathbf{m g} / \mathbf{g}_{\text {ads }}\right)$ & $\boldsymbol{r}^{\mathbf{2}}$ & $\boldsymbol{k}_{\mathbf{2}}\left(\mathrm{g}_{\mathrm{ads}} / \mathbf{m g} \mathbf{h}\right)$ & $\boldsymbol{q}_{\boldsymbol{e}}\left(\mathbf{m g} / \mathbf{g}_{\text {ads }}\right)$ & \\
\hline 0.95 & 0.57 & 0.3 & 0.984 & 0.364 & 0.475 & TOCN \\
0.966 & 0.18 & 14.5 & 0.981 & 0.16 & 12.262 & H-TOCN \\
\hline
\end{tabular}

Table 2. $\beta \theta$ values obtained from adsorption of gold onto the different types of $\operatorname{TOCN}\left(C_{0}=100 \mathrm{mg} / \mathrm{L}\right)$.

\begin{tabular}{cccc}
\hline \multicolumn{2}{c}{ TOCN } & \multicolumn{2}{c}{ H-TOCN } \\
\hline $\boldsymbol{t}$ (h) & $\boldsymbol{\beta} \boldsymbol{\theta}(\mathrm{g} / \mathrm{L})$ & $\boldsymbol{t} \mathbf{( h )}$ & $\boldsymbol{\beta} \boldsymbol{\theta}(\mathrm{g} / \mathrm{L})$ \\
\hline 4 & 5.80 & 4 & 4.95 \\
18 & 7.11 & 9 & 6.88 \\
23 & 7.52 & 19 & 7.40 \\
33 & 7.90 & 31 & 9.08 \\
48 & 8.43 & 48 & 9.57 \\
\hline
\end{tabular}

Additionally, the Weber-Morris intraparticle diffusion model was used to identify the adsorption mechanism of gold onto these two different types of TOCN by the intraparticle diffusion (IPD) model in term of mass transfer of Au surrounded by the TEMPO-oxidized cellulose nanofiber [32]. As mentioned earlier, TOCN has a porous structure, through which gold molecules may accordingly diffuse. A plot of $q_{t}$ versus $t^{0.5}$ (Figure 10) demonstrates that the whole adsorption process comprises of three distinct steps. The observed initial rapid increase in the slope relates to fast external surface adsorption, whereas the second section shows gradual adsorption, which is the rate-limiting step during intraparticle diffusion. Finally, the third portion of the plots outlines the equilibrium phase due to the reduced active site accessibility on the adsorbents and the low residual value of the remaining gold in the solution.
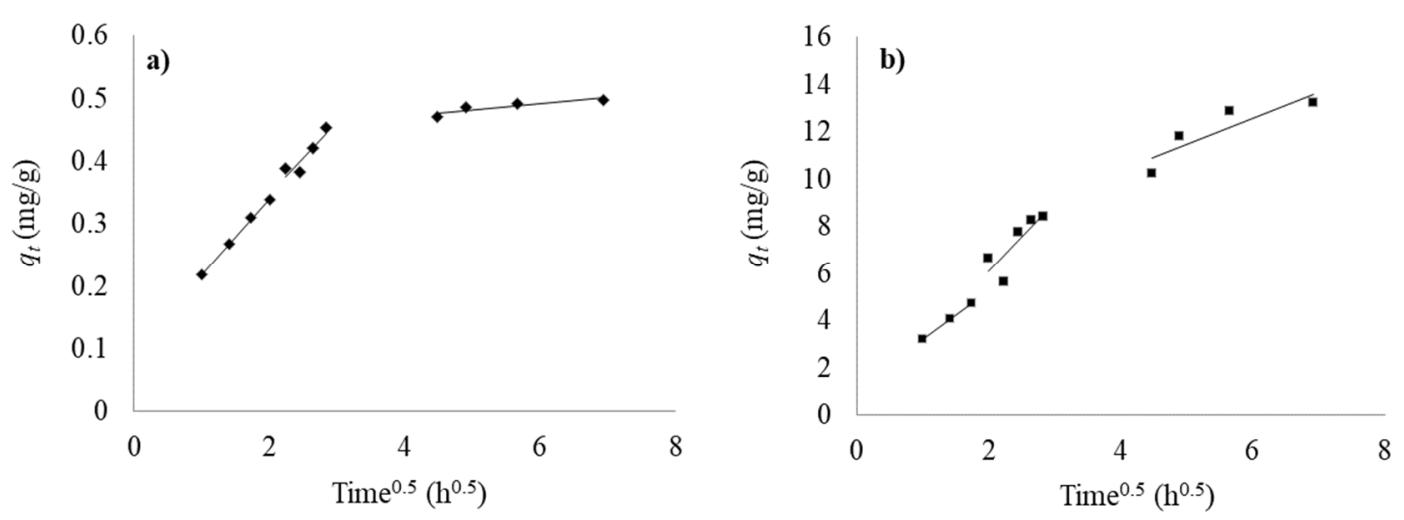

Figure 10. Intraparticle diffusion plots for gold adsorption onto (a) TOCN, (b) H-TOCN. 


\subsubsection{Equilibrium Study}

The basic characteristics of an adsorption process can be determined with an equilibrium study, whereas kinetic data are critical for adsorbent use optimization. Taken together they outline the relationship between the adsorbent amount and the dissolved adsorbate concentration in the liquid at equilibrium. In the work outlined here, the equilibrium study gold concentration was varied between $10-100 \mathrm{mg} / \mathrm{L}$ at $0.02 \mathrm{M}$ chloride solution in order to ascertain the relationship between adsorbed $\left(q_{e}\right)$ and solution concentration $\left(C_{e}\right)$ of gold under equilibrium conditions.

Langmuir, Freundlich and Langmuir-Freundlich isotherms (Equations (10)-(12)), which are commonly applied for many adsorbate/adsorbent systems, were employed to analyze the experimental equilibria data and to obtain the maximum adsorption capacity for each of the adsorbents investigated for gold removal.

$$
\begin{gathered}
q_{e}=\frac{q_{m} K_{L} C_{e}}{1+K C_{e}} \\
q_{e}=\left(K_{F} C_{e}\right)^{1 / n} \\
\frac{q}{q_{m}}=\frac{\left(K C_{e}\right)^{1 / n}}{1+\left(K C_{e}\right)^{1 / n}}
\end{gathered}
$$

where $q_{e}$ is the amount of adsorbate per unit mass of adsorbent at equilibrium, $q_{m}$ the maximum adsorption capacity to form a complete monolayer coverage on the surface bound at high equilibrium of adsorbate concentration $C_{e}(\mathrm{mg} / \mathrm{L}), K_{L}$, a model parameter that accounts for the degree of affinity between the adsorbate and adsorbent. $K_{F}, K$ and $n$ are constants.

Experimental data was modeled using the three equilibrium isotherm equations outlined above and Table 3 summarizes the correlation coefficients, $r^{2}$ values, and isotherm model constants obtained for gold adsorption onto the different types of TEMPO-oxidized nanofiber cellulose.

The Langmuir isotherm model gave rise to the highest $r^{2}$ values for each of the TEMPO-oxidized CNF, with maximum gold adsorption capacities of 15.44 and $0.48 \mathrm{mg} / \mathrm{g}$ for H-TOCNs and TOCNs, respectively. Overall, the equilibrium adsorption data demonstrates, heat treatment has a significant effect on the properties of the adsorbent when the maximum adsorption capacity of H-TOCN for recovery of gold from the chloride solution is considered.

Table 3. Parameters of the adsorption isotherms obtained for the adsorption of gold onto different types of the TOCN adsorbents.

\begin{tabular}{cccc}
\hline H-TOCN & TOCN & & \\
\hline 0.135 & 0.005 & $K_{L}(\mathrm{~L} / \mathrm{mg})$ & Langmuir \\
15.445 & 0.42 & $q_{m}(\mathrm{mg} / \mathrm{g})$ & \\
0.96 & 0.999 & $r^{2}$ & Freundlich \\
\hline 2.03 & 0.002 & $K_{F}\left(\mathrm{Lmg}^{(1-1 / \mathrm{n}))} / \mathrm{g}\right)$ & \\
1.53 & 0.6 & $n$ & \\
0.951 & 0.998 & $r^{2}$ & \\
\hline 0.012 & - & $K_{L-F}(\mathrm{~L} / \mathrm{mg})$ & \\
14.531 & 0.38 & $q_{m}(\mathrm{mg} / \mathrm{g})$ & $n$ \\
1.4 & 0.9 & $n$ & \\
0.953 & 0.786 & $r^{2}$ & \\
\hline
\end{tabular}

Generally, the adsorption efficiency was increased by drying TOCN, which might be attributed to strong electrostatic attraction between the Au-complex and H-TOCN.

Heat treatment of hydrogel TOCNF may result in more accessible carbonyl groups on neighboring fibrils proximal to the aldehyde group, subsequently these may react via an aldol mechanism in acidic media to a protonated form (Figure 11) [37,38]. 


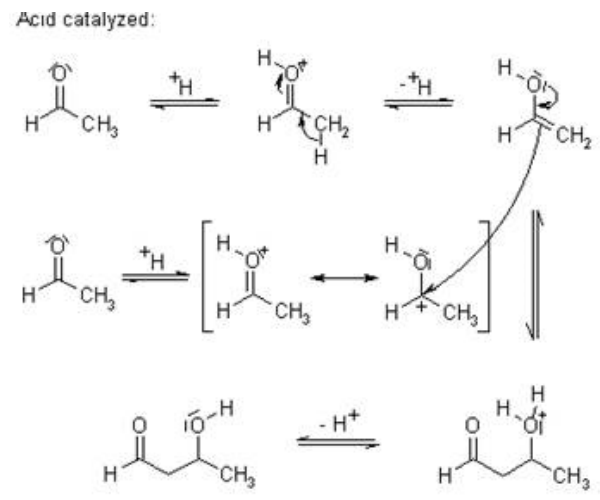

Figure 11. Mechanism of the aldol addition in acid catalyzed (after [38]).

Indeed, TOCN might be changed to a surface protonated carboxyl. In this regard, a more activated site is available for the interaction of protonated carboxylic ions with the ionic gold-complex molecules $\left(\mathrm{AuCl}_{4}{ }^{-}\right)$.

A comparative study of gold adsorption onto biopolymer adsorbents is summarized below (Table 4):

Table 4. Comparison of maximum adsorption capacities for gold on other biopolymer adsorbents.

\begin{tabular}{cccc}
\hline Adsorbent & Adsorption Capacity $(\mathbf{m g} / \mathbf{g})$ & Contact Time (h) & Reference \\
\hline Taurine-modified & 34.50 & 24 & {$[22]$} \\
cellulose & 11.86 & 9 & {$[39]$} \\
Carboxymethyl chitin & $* 1.22$ & 96 & {$[40]$} \\
Cotton cellulose & not reported & 48 & {$[41]$} \\
Fallen leaves & $15.44(\mathrm{mg} / \mathrm{g})$ & This study \\
H-TOCN & Oris
\end{tabular}

* Original report is $6.21(\mathrm{mmol} / \mathrm{g})$.

\section{Conclusions}

This study highlights that the recovery of gold using TEMPO-oxidized cellulose nanofibersparticularly the oven-dried form (H-TOCN) - are both feasible and effective for the capture of gold from dilute solutions of gold chloride solutions. Gold recoveries of $>90 \%$ can be readily achieved by $\mathrm{H}$-TOCN under ambient conditions after $48 \mathrm{~h}$ and mild agitation (130 rpm). Furthermore, an increase in temperature from room temperature to $90{ }^{\circ} \mathrm{C}$ results in efficiencies of $\sim 98 \%$ for TOCN, S-TOCN, and F-TOCN. Generally, owing to the hierarchical structure and tailorable adsorption behavior via surface reactivity, TOCN demonstrated the potential to adsorb gold from chloride containing solutions. It was determined that gold recovery was endothermic in nature as it was observed to occur spontaneously at both room and elevated temperatures. Moreover, the reaction was found to follow nonlinear pseudo second-order kinetics and the results from the Langmuir adsorption capacity calculations demonstrate that TOCN is a promising biomaterial for the adsorption of gold from chloride containing solutions.

Overall, it can be concluded that TOCN—either as a hydrogel or in a dry form—offers a sustainable solution for the treatment aqueous solution that contain gold, even under acidic conditions. Furthermore, the characteristics of H-TOCN and its high affinity for gold indicates that there is also the potential for the efficient recovery of other precious metals.

Supplementary Materials: The following are available online at http:/ /www.mdpi.com/2071-1050/11/5/1406/ s1, Figure S1: Pourbaix diagram of Au-Cu-H2O at $25^{\circ} \mathrm{C}$, Table S1: Thermodynamic parameters $($ WH-TOCN $=25$ $\mathrm{mg}, \mathrm{C} 0[\mathrm{Au}]=10-100 \mathrm{mg} / \mathrm{L}, \mathrm{C} 0[\mathrm{Cl}-]=0.02-1 \mathrm{M}, 48 \mathrm{~h}, 130 \mathrm{rpm}, \mathrm{pH}=2,10 \mathrm{~mL}$ sol.), Figure S2: Thermodynamic plot of $\ln$ Kc versus $1 / \mathrm{T}$. 
Author Contributions: Conceptualization, B.P.W., S.J. and M.L.; methodology, S.J.; validation, S.J.; formal analysis, S.J.; investigation, S.J. and B.P.W.; resources, T.T., E.K. and M.H.; writing-original draft preparation, S.J.; writing-review and editing, S.J., B.P.W., M.L., M.S., T.T. and E.K.; visualization, S.J. and B.P.W.; supervision, M.L.; project administration, B.P.W.; funding acquisition, M.S. and M.L.

Funding: The authors gratefully acknowledge the financial support provided by EU regional funds and the TEKES funded Jarogain project during Dr Jafari's research visit to Aalto University.

Acknowledgments: Emil Aaltonen Foundation's “Ympäristöystävällistä kultaa"and the Technology Industries of Finland Centennial/Jane and Aatos Erkko Foundations "Future Makers: Biorefinery Side Stream Materials for Advanced Biopolymer Materials (BioPolyMet) project funding is also acknowledged. Also, we would like to acknowledge FinnCERES. This work was a part of the Academy of Finland's Flagship Programme under Projects No. 318890 and 318891 (Competence Center for Materials Bioeconomy, FinnCERES. Petteri Halli is recognised for the excellent laboratory assistance at Aalto University. This work also made use of the facilities of the Academy of Finland funded RawMatTERS Finland Infrastructure Powder Characterisation Unit (RAMI-PCU) based at Aalto University.

Conflicts of Interest: The authors declare no conflict of interest.

\section{References}

1. Natarajan, G.; Tay, S.B.; Yew, W.S.; Ting, Y. Engineered strains enhance gold biorecovery from electronic scrap. Miner. Eng. 2015, 75, 32-37. [CrossRef]

2. Cui, J.; Zhang, L. Metallurgical recovery of metals from electronic waste: A review. J. Hazard. Mater. 2008, 158, 228-256. [CrossRef] [PubMed]

3. Moats, M.; Wang, S.; Filzwieser, A.; Siegmund, A.; Davenport, W.; Robinson, T. Survey of Copper Electrorefining Operations; Copper, 2016; Available online: http://www.copper2016.jp/program/html/session-06.html (accessed on 6 March 2019).

4. Lundström, M.; Ahtiainen, R.; Haakana, T.; O'callaghan, J. Techno-economical observations related to outotec gold chloride process. In Proceedings of the ALTA, Perth, Australia, 24-31 May 2014.

5. Lampinen, M.; Seisko, S.; Forsström, O.; Laari, A.; Aromaa, J.; Lundström, M.; Koiranen, T. Mechanism and kinetics of gold leaching by cupric chloride. Hydrometallurgy 2017, 169, 103-111. [CrossRef]

6. Hilson, G.; Monhemius, A.J. Alternatives to cyanide in the gold mining industry: What prospects for the future? J. Clean Prod. 2006, 14, 1158-1167. [CrossRef]

7. Crundwell, F.; Moats, M.; Ramachandran, V.; Robinson, T.; Davenport, W.G. Extractive Metallurgy of Nickel, Cobalt and Platinum Group Metals; Elsevier: Oxford, UK, 2011; p. 610.

8. Kurniawan, T.A.; Sillanpää, M.E.T.; Sillanpää, M. Nanoadsorbents for Remediation of Aquatic Environment: Local and Practical Solutions for Global Water Pollution Problems. Crit. Rev. Environ. Sci. Technol. 2012, 42, 1233-1295. [CrossRef]

9. Dubey, S.P.; Dwivedi, A.D.; Kim, I.; Sillanpää, M.; Kwon, Y.; Lee, C. Synthesis of graphene-carbon sphere hybrid aerogel with silver nanoparticles and its catalytic and adsorption applications. Chem. Eng. J. 2014, 244, 160-167. [CrossRef]

10. Tasdelen, C.; Aktas, S.; Acma, E.; Guvenilir, Y. Gold recovery from dilute gold solutions using DEAE-cellulose. Hydrometallurgy 2009, 96, 253-257. [CrossRef]

11. Ogata, T.; Nakano, Y. Mechanisms of gold recovery from aqueous solutions using a novel tannin gel adsorbent synthesized from natural condensed tannin. Water Res. 2005, 39, 4281-4286. [CrossRef] [PubMed]

12. Hokkanen, S.; Repo, E.; Suopajärvi, T.; Liimatainen, H.; Niinimaa, J.; Sillanpää, M. Adsorption of Ni(II), $\mathrm{Cu}(\mathrm{II})$ and $\mathrm{Cd}(\mathrm{II})$ from aqueous solutions by amino modified nanostructured microfibrillated cellulose. Cellulose 2014, 21, 1471-1487. [CrossRef]

13. Hokkanen, S.; Repo, E.; Sillanpää, M. Removal of heavy metals from aqueous solutions by succinic anhydride modified mercerized nanocellulose. Chem. Eng. J. 2013, 223, 40-47. [CrossRef]

14. Gestranius, M.; Stenius, P.; Kontturi, E.; Sjöblom, J.; Tammelin, T. Phase behaviour and droplet size of oil-in-water Pickering emulsions stabilised with plant-derived nanocellulosic materials. Colloids Surf. Physicochem. Eng. Aspects 2017, 519, 60-70. [CrossRef]

15. Salmon, S.; Hudson, S.M. Crystal Morphology, Biosynthesis, and Physical Assembly of Cellulose, Chitin, and Chitosan. J. Macromol. Sci. Part C 1997, 37, 199-276. [CrossRef]

16. Habibi, Y.; Lucia, L.A.; Rojas, O.J. Cellulose Nanocrystals: Chemistry, Self-Assembly, and Applications. Chem. Rev. 2010, 110, 3479-3500. [CrossRef] [PubMed] 
17. Hokkanen, S.; Bhatnagar, A.; Sillanpää, M. A review on modification methods to cellulose-based adsorbents to improve adsorption capacity. Water Res. 2016, 91, 156-173. [CrossRef] [PubMed]

18. O'Connell, D.W.; Birkinshaw, C.; O'Dwyer, T.F. Heavy metal adsorbents prepared from the modification of cellulose: A review. Bioresour. Technol. 2008, 99, 6709-6724. [CrossRef] [PubMed]

19. Isobe, N.; Chen, X.; Kim, U.J.; Kimura, S.; Wada, M.; Saito, T.; Isogai, A. TEMPO-oxidized cellulose hydrogel as a high-capacity and reusable heavy metal ion adsorbent. J. Hazard. Mater. 2013, 260, 195-201. [CrossRef] [PubMed]

20. Peyre, J.; Paakkonen, T.; Reza, M.; Kontturi, E. Simultaneous preparation of cellulose nanocrystals and micron-sized porous colloidal particles of cellulose by TEMPO-mediated oxidation. Green Chem. 2015, 17, 808-811. [CrossRef]

21. Dwivedi, A.D.; Dubey, S.P.; Hokkanen, S.; Fallah, R.N.; Sillanpää, M. Recovery of gold from aqueous solutions by taurine modified cellulose: An adsorptive-reduction pathway. Chem. Eng. J. 2014, 255, 97-106. [CrossRef]

22. Saito, T.; Nishiyama, Y.; Putaux, J.; Vignon, M.; Isogai, A. Homogeneous Suspensions of Individualized Microfibrils from TEMPO-Catalyzed Oxidation of Native Cellulose. Biomacromolecules 2006, 7, 1687-1691. [CrossRef] [PubMed]

23. Liu, P.; Borrell, P.F.; Božič, M.; Kokol, V.; Oksman, K.; Mathew, A.P. Nanocelluloses and their phosphorylated derivatives for selective adsorption of $\mathrm{Ag}^{+}, \mathrm{Cu}^{2+}$ and $\mathrm{Fe}^{3+}$ from industrial effluents. J. Hazard. Mater. 2015, 294, 177-185. [CrossRef] [PubMed]

24. Hubbe, M.; Rojas, O.; Lucia, L.; Sain, M. Cellulosic nanocomposites: A Review. BioResources 2008, 3, 929-980.

25. Leikola, M.; Elomaa, H.; Jafari, S.H.; Rintala, L.; Wilson, B.; Lundström, M. Possibilities and challenges in gold chloride processing. In Proceedings of the Gold-Precious Metal Conference, Vienna, Austria, 18-20 October 2015.

26. Vlassopoulos, D.; Wood, S.A.; Mucci, A. Gold speciation in natural waters: II. The importance of organic complexing-Experiments with some simple model ligands. Geochim. Cosmochim. Acta 1990, 54, 1575-1586. [CrossRef]

27. Brunauer, S.; Emmett, P.H.; Teller, E. Adsorption of Gases in Multimolecular Layers. J. Am. Chem. Soc. 1938, 60, 309-319. [CrossRef]

28. Barrett, E.P.; Joyner, L.G.; Halenda, P.P. The Determination of Pore Volume and Area Distributions in Porous Substances. I. Computations from Nitrogen Isotherms. J. Am. Chem. Soc. 1951, 73, 373-380. [CrossRef]

29. Ahola, S.; Salmi, J.; Johansson, L.S.; Laine, J.; Österberg, M. Model Films from Native Cellulose Nanofibrils. Preparation, Swelling, and Surface Interactions. Biomacromolecules 2008, 9, 1273-1282. [CrossRef] [PubMed]

30. Sing, K.S. Reporting physisorption data for gas/solid systems with special reference to the determination of surface area and porosity (Recommendations 1984). Pure Appl. Chem. 1985, 57, 603-619. [CrossRef]

31. Nicol, M.J. Electrochemical and kinetic investigation of the behavior of gold in chloride solutions: The gold(III)-gold(I) reaction on platinum and the disproportionation of gold(I). Nati. Inst. for Met. 1981.

32. Liimatainen, H.; Visanko, M.; Sirviä, J.A.; Hormi, O.E.O.; Niinimaki, J. Enhancement of the Nanofibrillation of Wood Cellulose through Sequential Periodate-Chlorite Oxidation. Biomacromolecules 2012, 13, 1592-1597. [CrossRef]

33. Jiang, F.; Hsieh, Y. Self-assembling of TEMPO Oxidized Cellulose Nanofibrils as Affected by Protonation of Surface Carboxyls and Drying Methods. ACS Sustain. Chem. Eng. 2016, 4, 1041-1049. [CrossRef]

34. Alguacil, F.J.; Adeva, P.; Alonso, M. Processing of residual gold (III) solutions via ion exchange. Gold Bull. 2005, 38, 9-13. [CrossRef]

35. Azizian, S. Kinetic models of sorption: A theoretical analysis. J. Colloid Interface Sci. 2004, 276, 47-52. [CrossRef] [PubMed]

36. Jafari, S.; Yahyaei, B.; Kusiak-Nejman, E.; Sillanpää, M. The influence of carbonization temperature on the modification of $\mathrm{TiO}_{2}$ in the removal of methyl orange from aqueous solution by adsorption. Desalin. Water Treat. 2016, 57, 18825-18835. [CrossRef]

37. Seki, A.; Ishiwata, F.; Takizawa, Y.; Asami, M. Crossed aldol reaction using cross-linked polymer-bound lithium dialkylamide. Tetrahedron 2004, 60, 5001-5011. [CrossRef]

38. Jonathan, C.; Nick, G.; Stuart, W. Organic Chemistry, 2nd ed.; Oxford University Press: Oxford, UK, 2012. 
39. Wasikiewicz, J.M.; Nagasawa, N.; Tamada, M.; Mitomo, H.; Yoshii, F. Adsorption of metal ions by carboxymethyl chitin and carboxymethyl chitosan hydrogels. Nucl. Instrum. Methods Phys. Res. Sect. B Beam Interact. Mater. At. 2005, 236, 617-623. [CrossRef]

40. Pangeni, B.; Paudyal, H.; Inoue, K.; Kawakita, H.; Ohto, K.; Alam, S. Selective recovery of gold(III) using cotton cellulose treated with concentrated sulfuric acid. Cellulose 2012, 19, 381-391. [CrossRef]

41. Aktas, S.; Gozuak, B.; Acma, H.; Ozalp, M.R.; Acma, E. Gold recovery from chloride solutions using fallen leaves. Environ. Chem. Lett. 2011, 9, 47-53. [CrossRef] 